\title{
Evolução da Cobertura Florestal no Município de Santa Maria de Jetibá - ES
}

\author{
Alexandre Rosa dos Santos ${ }^{1}$, Helio Carreço de Almeida Junior ${ }^{2}$, \\ Fernando Coelho Eugenio ${ }^{1}$
}

${ }^{1}$ Departamento de Engenharia Rural, Universidade Federal do Espírito Santo - UFES

${ }^{2}$ Departamento de Geografia, Universidade Federal do Espírito Santo - UFES

\begin{abstract}
RESUMO
Por meio do mapeamento da vegetação a partir da década de 1970, anos de 1970 e 1971, e anos de 2002 e 2005, este trabalho avaliou os níveis de fragmentação da vegetação nativa do município de Santa Maria de Jetibá - ES. Para tanto, utilizaram-se fotografias aéreas produzidas pelos serviços de aerofotogrametria realizados em 1970/71, uma imagem de satélite Landsat 7 com $15 \mathrm{~m}$ de resolução espacial do ano de 2002, além de uma imagem de satélite SPOT $5 \mathrm{~m}$ do ano de 2005, para melhor visualização do fenômeno em estudo. Por meio de diferentes técnicas de classificação de imagens orbitais, as imagens foram classificadas e os produtos, posteriormente aferidos com visitas de campo, visando comparar as classes de fragmentação da vegetação nativa processadas e as reais. Considerou-se a classificação que melhor se adaptou às realidades do município estudado na tentativa de alcançar os melhores resultados. Após a quantificação das áreas de mata no município, desde a década de 1970 até atualmente, foi possível saber se houve incremento florestal ou desmatamento nesses 35 anos propostos.
\end{abstract}

Palavras-chave: evolução temporal, desmatamento, cobertura florestal, sensoriamento remoto.

\section{Evolution of Forest Fragmentation in the Municipality of Santa Maria de Jetiba - ES}

\begin{abstract}
By mapping the forest from 1970 to 1971 and in 2005, this study evaluated the levels of forest fragmentation in Santa Maria de Jetiba - State of Espirito Santo. To this end, aerial photographs were produced by aerophotography services as follows: Landsat satellite image with $15 \mathrm{~m}$ spatial resolution of 2002 in 1970/71 and SPOT satellite with $5 \mathrm{~m}$ in 2005. By using different classification techniques, the satellite images were classified and the products were subsequently assessed on field visits. The classification that best adapted to the reality of the municipality studied was considered in an attempt to achieve the best results. After the quantification of the forest areas in the municipality, from the 1970's until today, it was possible to learn whether there was forest increase or deforestation over these 35 years.
\end{abstract}

Keywords: temporal evolution, deforestation, fragmentation, geotechnology. 


\section{INTRODUÇÃO}

O IBGE (2001) define o sensoriamento remoto como sendo o processo de aquisição de dados sobre um objeto ou cena à distância; ou, mais especificamente, o processo de obtenção de informações sem entrar em contato direto com a área ou o fenômeno sob investigação.

O sensoriamento remoto é uma tecnologia que obtém medidas de um objeto sem tocá-lo fisicamente e oferece um vasto arsenal de produtos característicos por imagens de diferentes resoluções espaciais e espectrais. O Processamento Digital de Imagens (PDI) é um conjunto de técnicas que tem como objetivo principal remover os vários tipos de degradações e distorções inerentes aos processos de aquisição, transmissão e visualização das imagens coletadas, facilitando a extração de informações (Crósta, 1992).

O objetivo do presente trabalho é realizar um estudo sobre a evolução da fragmentação da Mata Atlântica no município de Santa Maria de Jetibá, com o uso de fotografias aéreas, imagens de satélite e auxílio de programas de geotecnologia, de maneira a indicar qual o histórico da fragmentação florestal nos últimos 30 anos, além de constatar se houve incremento florestal ou desmatamento na região.

Para tanto, foi efetuada uma interpretação das fotografias aéreas disponíveis a partir da década de 1970, utilizando-se o material produzido pelos serviços de aerofotogrametria realizados em 1970/71. A partir da década de 1980, foram utilizadas imagens de satélite Landsat, além de uma imagem SPOT $5 \mathrm{~m}$ de 2005, com o objetivo de identificar o padrão de fragmentação florestal, identificando as áreas de desmatamento, bem como de regeneração da floresta. O surgimento das imagens de satélite possibilitou, além da criação de um nível de percepção mais global, complementar as fotografias aéreas e os levantamentos de campo, com a obtenção de informações radiométricas digitais de grandes extensões da superfície terrestre.

Embora a resolução espacial dos produtos de sensoriamento remoto, na maioria das vezes, não permita a observação direta da fauna, é possível, por meio do mapeamento dos habitats das espécies, estabelecer áreas com características compatíveis às necessidades destas. Estudos complementares de campo sobre a ocorrência e a densidade de certas espécies da fauna nessas áreas permitem o mapeamento das zonas de ocorrência e quantificação dos indivíduos. A ideia de integrar sensoriamento remoto e SIG para estruturar e manipular bases de dados tem auxiliado a tarefa de mapeamento de habitats de várias espécies faunísticas.

Entretanto, uma das preocupações em relação ao processamento automatizado de imagens de satélite é a questão de confiabilidade dos mapeamentos efetuados. Existem várias formas de se obter a exatidão dos mapeamentos. Richards (1996) definiu e discutiu a performance dos classificadores e a exatidão dos mapeamentos, considerando a amostragem de campo uma etapa fundamental dos trabalhos.

$\mathrm{Na}$ tentativa de aprimorar as classificações automáticas das imagens de satélite, alguns trabalhos procuraram considerar elementos adicionais ao valor radiométrico do próprio pixel, como, por exemplo, o contexto de inserção (vizinhança), visando com isso melhorar a fidelidade dos mapeamentos. A introdução de novos elementos aos processos automáticos de classificação de imagens de satélite tem por objetivo aproximar esse tipo de classificação à interpretação analógica, na qual muito do conhecimento e da experiência do próprio autor é levado em consideração, eliminando, porém, as imprecisões cometidas pelas limitações do olho humano (Ryherd \& Woodcock, 1996).

\section{MATERIAL E MÉTODOS}

A área de estudo compreende o município de Santa Maria de Jetibá, localizado na região centroserrana do Estado do Espírito Santo, com sede nas coordenadas $20^{\circ} 02^{\prime} 0,85^{\prime \prime} \mathrm{S}$ e $40^{\circ} 41^{\prime} 58,55^{\prime \prime} \mathrm{W}$ (Figura 1).

O município está situado na formação geomorfológica do Complexo Cristalino, com altitudes variando entre 600 e $1200 \mathrm{~m}$, localizado no domínio fitogeográfico de Mata Atlântica Submontana a Montana. É uma região que foi colonizada a partir do final do século XIX por imigrantes europeus oriundos, principalmente, da antiga Pomerânia, que implantaram um 


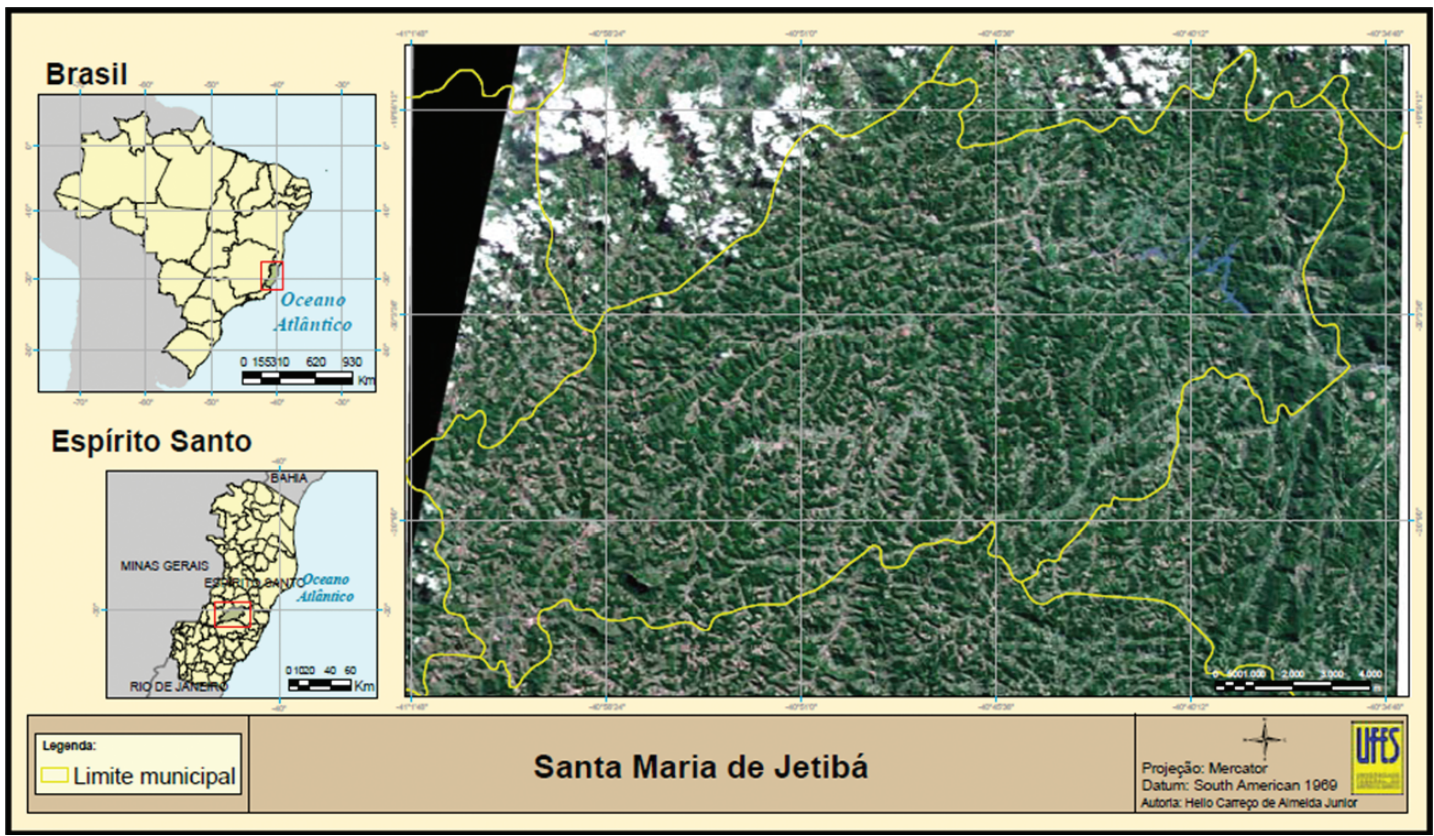

Figura 1. Localização da área de estudo.

Figure 1. Location of the study area.

sistema agrícola de pequenas propriedades rurais, desenvolvendo a agricultura familiar.

O relevo de Santa Maria de Jetibá apresenta-se de forma montanhosa a fortemente ondulado, com altitudes oscilando entre $350 \mathrm{~m}$, na região chamada Suíça, e 1.462 m, no Distrito de Garrafão. A sede está a uma altitude média de $710 \mathrm{~m}$. De acordo com a classificação de Köppen, verifica-se que o Município de Santa Maria de Jetibá enquadra-se dentro dos tipos climáticos $\mathrm{Cf}$ e $\mathrm{Cw}$, com variações entre Cfa, Cfb e Cwa.

A formação florestal dominante do município enquadra-se como floresta perenifólia densa, com sub-bosques densos; formação higrófila e ombrófila, com árvores de 20 a $30 \mathrm{~m}$ de altura e diâmetros variáveis, sempre verdes durante o ano, ocorrendo em áreas praticamente sem estação seca marcante, com precipitações regulares. Distribui-se em lugares elevados com altitudes acima de $600 \mathrm{~m}$. Nas áreas mais altas, há ocorrência de floresta subperenifólia, sempre verde, decídua em parte. Ocorre em regiões com estação seca de 2 a 3 meses (déficit hídrico) e mais de $1.000 \mathrm{~mm}$ de precipitação pluviométrica total anual.

\subsection{Classificação visual do mosaico de fotos aéreas}

A primeira tarefa desempenhada foi digitalizar as fotografias aéreas obtidas nos anos de 1970/71 que cobrem o município de Santa Maria de Jetibá. O número de fotografias necessárias para a cobertura de uma área de interesse deve atender aos requisitos de estereoscopia e outros. Uma cobertura aérea deve prever a Superposição Longitudinal entre fotos consecutivas, que geralmente é da ordem de $60 \%$. De maneira semelhante, entre faixas de fotos, existe uma Superposição Lateral que é da ordem de $30 \%$.

Assim, a área de cobertura única, sem superposição, de uma fotografia aérea corresponderia ao produto da dimensão representativa de $40 \%$ do lado da foto no sentido longitudinal e 70\% do lado da foto no sentido lateral.

O Instituto de Defesa Agropecuária e Florestal do Espírito Santo (IDAF) cedeu 139 fotos para serem escaneadas. As fotos foram levadas para uma copiadora possuidora de scanner A3 profissional, sendo o produto final da scanerização um arquivo raster. O scanner mais indicado para digitalizar as fotos seria o tipo tambor, que minimiza bastante 
as distorções de borda; entretanto, foi utilizado um scanner de mesa tamanho A3. Para uma melhor confiabilidade na posterior análise das imagens, as mesmas foram digitalizadas com uma resolução de 900 dpis.

É inerente a todo processo de captura de dados a existência de erros. Estes podem existir nos dados originais ou serem derivados da interpretação das fontes primárias. Entretanto, é indispensável transformar todos os dados espaciais em formato digital, para que estes possam ser manipulados em ambiente de SIGs (Sistemas de Informações Geográficas).

Com todas as fotos digitalizadas, o passo seguinte foi georreferenciá-las, utilizando-se o programa ERDAS Imagine 8.5. As fotos foram retificadas baseando-se em coordenadas UTM de uma imagem do satélite LANDSAT e de cartas topográficas da região, na escala de 1:50.000 (IBGE, 1975).

Essa etapa consiste em coletar pontos de controle na imagem georreferenciada e correlacioná-los na foto a ser retificada; dessa forma, os pontos coletados nas duas imagens corresponderão ao mesmo local. A partir do terceiro ponto, o programa os interpola de forma que os próximos a serem coletados já caem nos locais corretos, necessitando apenas de pequenas alterações, ao mesmo tempo em que calcula o erro operacional. A quantificação do erro operacional é feita utilizando-se o erro médio quadrático (Root Meam Square - RMS) no eixo das ordenadas e das abscissas e, por fim, o cálculo do RMS total será representado graficamente como a hipotenusa de um triângulo retângulo. O RMS permitido pode ser calculado segundo três perspectivas diferentes: a escala do mapa, a probabilidade de erro de um objetivo a ser alcançado e o produto final esperado. O RMS permitido requer que $90 \%$ de erros acidentais não devem ser maiores que 1,64\% do RMS calculado, isso é, $1,64 \%$ desvios padrões, assumindo uma distribuição normal dos erros.

De cada foto, foram obtidos cerca de 20 pontos de controle, sendo o RMS inferior a 1,0 para assegurar a precisão do georreferenciamento. Feito isso, tirou-se uma nova amostra da imagem que está sendo retificada, ou seja, gera-se um novo arquivo georreferenciado na extensão do ERDAS ( ${ }^{*}$.img), seguindo o método estatístico Bilinear Interpolation.
Com as 139 fotos georreferenciadas, foi possível fazer um mosaico das mesmas. Aproveitando-se dos $60 \%$ de sobreposição, foram cortadas partes das bordas das fotos a fim de eliminar um pouco dos efeitos de distorção que costumam ocorrer.

Para efetuar a junção das fotos, foram utilizadas as ferramentas de mosaico disponíveis no software ERDAS Imagine.

Após a adição das fotos desejadas, foi possível escolher quais delas seriam mais indicadas a ficar por cima e qual o método a ser usado no processo de mosaicagem. No caso em questão, o mais indicado é o método "feather", ou seja, quando há sobreposição das fotos, ocorre uma espécie de alisamento que atenua as possíveis diferenças que podem ocorrer em função da distorção de borda. Dessa forma, obtevese o mosaico de fotos aéreas de 1970 cobrindo todo o município de Santa Maria de Jetibá.

Concluído o mosaico, a etapa seguinte do plano de trabalho foi realizar a classificação do uso da terra com base nas fotografias aéreas em três categorias: mata em estágio médio a avançado de regeneração; mata em estágio inicial de regeneração, e área sem cobertura de mata nativa, como, por exemplo: áreas agriculturadas, pastagens, edificações, dentre outros tipos de uso da terra.

A classificação de objetos ou fenômenos é feita pela escolha das características que os descrevem para diferenciá-los entre si. Na definição matemática, usase o espaço de atributos (feature space), que é essencial para se entender como funciona a classificação de imagens multiespectrais. No processamento digital, a cada eixo desse espaço são atribuídos os níveis de cinza de uma determinada banda espectral.

Utilizou-se o princípio de classificação supervisionada, o qualébaseado no uso de algoritmos para se determinar os pixels que representam valores de reflexão característicos para uma determinada classe; foi utilizada tal classificação, pois é a mais empregada na análise quantitativa dos dados de sensoriamento remoto.

Foi feita uma prévia classificação supervisionada da imagem, mas os resultados obtidos não foram satisfatórios. O principal problema encontrado estava na diferença de contraste das fotos, como pode ser observado na Figura 1. Essa diferenciação de contrastes influi diretamente na classificação 
supervisionada, já que o classificador (programa) consegue calcular todos os níveis de cinza e a frequências de ondas. Assim, se a imagem não mantém um padrão de cores em sua totalidade, as categorias de classes calculadas não correspondem à realidade.

Uma das soluções propostas seria fazer um tratamento avançado na imagem com programas específicos, com o intuito de uniformizar o padrão de cor. Entretanto, optou-se por fazer uma classificação visual da imagem das categorias propostas. Apesar de ser um processo mais demorado e trabalhoso, os resultados do mapeamento são bastante confiáveis.

Os critérios utilizados para mapear os fragmentos florestais, separando-os em mata em estágio médio a avançado de regeneração, e mata em estágio inicial de regeneração, foram baseados na resolução no 34 , de 7 de dezembro de 1994 do CONAMA.

Foram digitalizados todos os fragmentos florestais do município e então divididos por atributo, de acordo com a resolução do CONAMA.

\subsection{Classificação supervisionada de imagem Landsat}

No prosseguimento do estudo, deu-se início à classificação de uma imagem de satélite recente quanto a presença ou ausência de cobertura de mata nativa. A imagem utilizada foi do satélite LANDSAT ETM+.

As imagens (ou cenas) LANDSAT-TM cobrem, cada uma, a área de $185 \times 185 \mathrm{~km}$, equivalente a 28 segundos de dados. Os produtos digitais contêm todas as bandas. Cada banda representa a resposta do solo em certa faixa espectral, variando entre as bandas azul e infravermelho termal, totalizando sete bandas espectrais (Santos et al., 2010).

A cena utilizada foi coletada em 01/maio/2002, na órbita 216, ponto 074 . Trata-se de uma fusão das Bandas 5R 4G 3B + PAN, com interpolação bilinear. As Bandas 3, 4 e 5 mostram mais claramente os limites entre o solo e a água, com a vegetação mais discriminada, aparecendo em tonalidades de verde e rosa.

A utilização de mais de uma fonte de informações orbitais, muitas vezes pode auxiliar detecção, identificação, delimitação e caracterização da cobertura vegetal, uma vez que diferentes horários de aquisição, ângulos de visada, resolução espectral e espacial dos satélites resultam em respostas distintas e, muitas vezes, complementares.

Iniciando-se o processo de classificação supervisionada da imagem, foram seguidos os seguintes passos, considerados essenciais:

- Definição das classes nas quais a imagem vai ser dividida. No caso em questão, foram definidas as seguintes classes: mata em estágio médio a avançado de regeneração, e mata em estágio inicial de regeneração.

- Escolha de amostras de treinamento para cada classe baseada no tamanho amostral, por meio da função binomial (Congalton, 1988; Congalton \& Green, 1999; Thompson, 2002). A função utilizada para estimativa do número de pontos amostrais é apresentada na Equação 1:

$n=\frac{\left(Z_{\alpha / 2}\right)^{2} p \cdot q}{E^{2}}$

em que: $\mathrm{n}=$ número total de elementos a serem amostrados; $\mathrm{Z}=$ distribuição normal padrão; $\alpha=$ nível de significância; $p=$ exatidão desejada; $\mathrm{q}=(1-\mathrm{p}) ; \mathrm{E}=$ erro de amostragem.

- Aplicação de um algoritmo de classificação em que todos os pixels são classificados conforme o método estatístico escolhido (por exemplo, Métodos do Paralelepípedo, da Mínima Distância, do Mapeador de ângulo espectral - "Spectral Angle Mapper"-SAM - e da Máxima Verossimilhança).

A interpretação visual é limitada à observação de apenas três bandas, enquanto as classificações automáticas são aplicadas a qualquer número de bandas que se queira.

O classificador da distância de Mahalanobis é similar ao da distância mínima e usa estatísticas para cada classe; porém, esse método supõe que a covariança das amostras é igual e, portanto, é um classificador ainda mais rápido que o método de mínima distância.

Dos métodos de classificação citados, O ERDAS dispõe de três: Maximum Likelihood, Mahalanobis Distance e Minimum Distance.

Como referido anteriormente, após a definição das classes nas quais a imagem seria dividida, deu-se início à criação de assinaturas espectrais utilizando- 
se a caixa de diálogo signature editor do ERDAS Imagine. Esse processo consiste na digitalização de polígonos nas áreas correspondentes às classes definidas.

Cabe lembrar que quanto maior for o número de assinaturas colhidas em toda área compreendida pela imagem, mais confiável será a classificação supervisionada, independentemente do método utilizado pelo classificador (Brites, 1996). A estratégia de alimentar o classificador com as mais variadas formas de apresentação das classes temáticas foi responsável pelo índice de exatidão obtido. $\mathrm{O}$ classificador supervisionado utilizado possibilitou um aumento na fidelidade do mapeamento, uma vez que considerou cada amostra isoladamente para a constituição da nuvem de distribuição das classes temáticas, evitando-se assim a criação de nuvens com altos valores de dispersão em torno da média.

\subsection{Classificação visual de imagem SPOT}

O trabalho inicial foi efetuar a correção geométrica da imagem, que consistiu em um processo semelhante ao explicado anteriormente com as fotografias aéreas. A imagem foi retificada baseando-se em coordenadas UTM de uma imagem do satélite LANDSAT e de cartas topográficas da região, na escala de 1:50.000 (IBGE, 1975). O georreferenciamento se deu pelo programa ERDAS Imagine e envolveu três etapas:

- Obtenção de coordenadas de pontos de controle terrestre;

- Interpolação espacial da imagem empregando-se os pontos de controle coletados para ajuste de equações polinomiais de primeira ordem (linear);

- Interpolação da intensidade de brilho utilizandose o método do vizinho mais próximo, o qual não altera o valor de brilho dos pixels, evitando-se problemas relacionados à discriminação de feições terrestres em processos de classificação de imagem.

Concluída a correção geométrica da imagem, iniciou-se o processo de classificação supervisionada, com a coleta de assinaturas de classe para mata em estágio médio a avançado de regeneração, e estágio inicial. Entretanto, os algoritmos de classificação supervisionada utilizados não mostraram resultados satisfatórios, o que não era esperado, posto que se trata de uma imagem de alta resolução. Diante desse problema, fez-se necessário uma pesquisa aprofundada sobre o estado da arte em classificação de imagens de alta resolução e as técnicas utilizadas atualmente.

Com a recente disponibilidade de imagens de alta resolução produzidas por sensores orbitais como IKONOS, SPOT e QUICKBIRD, tornou-se possível modelar características da cobertura do solo com maior nível de detalhes do que era possível com imagens de média ou baixa resolução. Imagens SPOT, por exemplo, têm pixels de $5 \mathrm{~m}$ por $5 \mathrm{~m}$. Essa resolução é o suficiente para visualizar com detalhes, por exemplo, o teto de uma casa, as árvores e estradas.

Nesse contexto, trabalhos podem ser desenvolvidos utilizando-se diferentes técnicas, automáticas ou não, de representação e interpretação em imagens de alta resolução. Essas técnicas envolvem não somente diferentes modelos de tratamento de dados, mas também englobam diferentes métodos de representação da informação relevante para a tarefa de interpretação, tais como os baseados em pixel (Vilela, 2002).

Por falta de um classificador que atendesse às especificações da imagem SPOT, a sua classificação foi efetuada por meio de interpretação visual, com digitalização em tela das feições identificadas.

\section{RESULTADOS E DISCUSSÃO}

De posse das três classificações, para os anos de 1970, 2002 e 2005, foi possível contabilizar se houve incremento de mata ou desmatamento nos últimos 35 anos no município estudado. Os procedimentos de utilização de ferramentas de SIG para tais análises estão descritos a seguir, juntamente com os resultados obtidos.

O programa de Geotecnologia utilizado para a quantificação e o mapeamento dos fragmentos florestais de Santa Maria de Jetibá foi o ArcGIS 9. Foram digitalizados todos os fragmentos florestais do município e então divididos por atributo, de acordo com a resolução do CONAMA. Dessa forma, obtevese um mapa contendo as categorias de estágio inicial de regeneração florestal e estágio médio a avançado de regeneração (Figura 2).

Todos os algoritmos de classificação disponíveis no ERDAS foram testados nessa etapa do trabalho; entretanto, o método que melhor respondeu às 


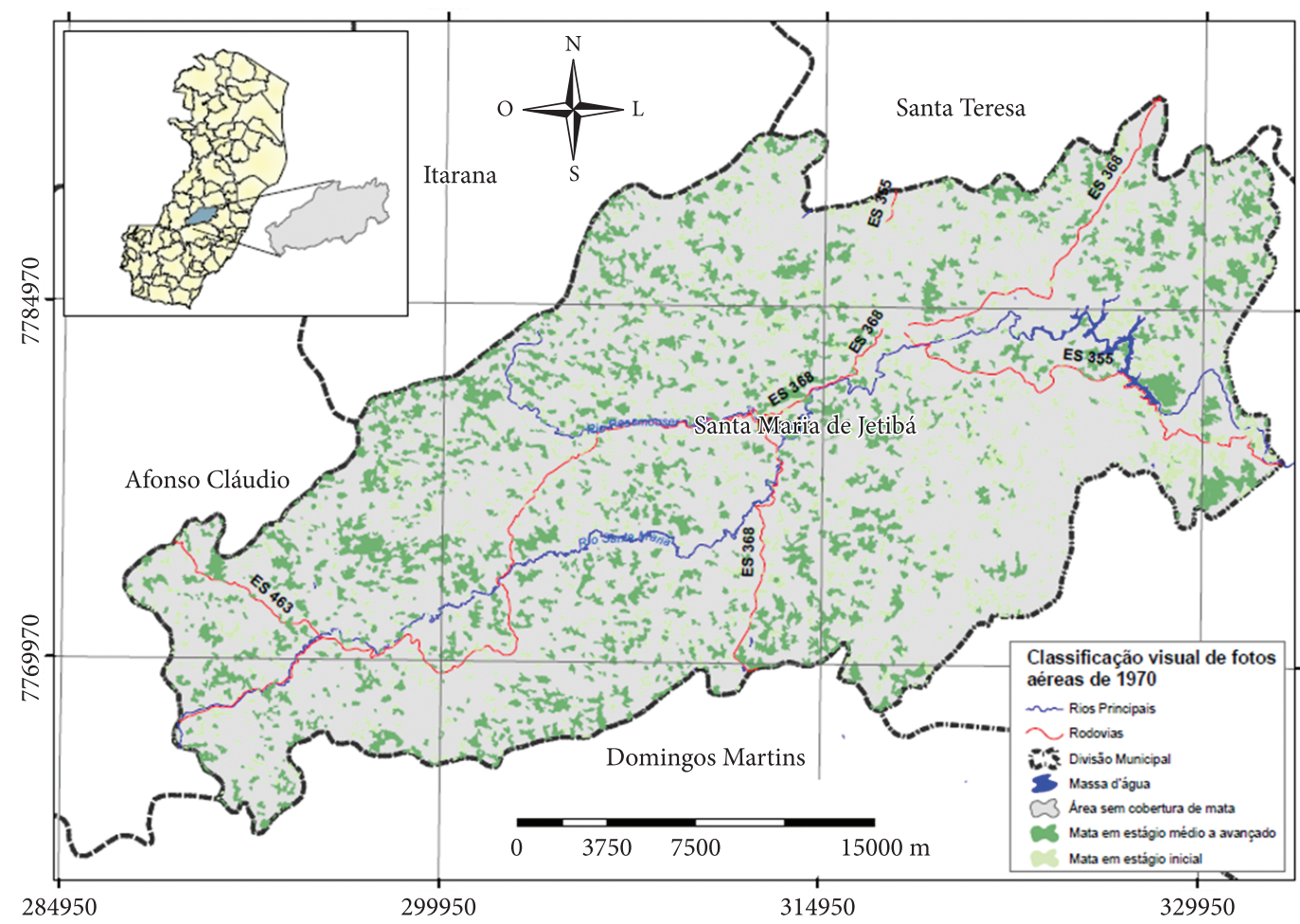

Figura 2. Classificação visual do mosaico de fotos aéreas de 1970.

Figure 2. Classification visual mosaic of aerial photos from 1970.

expectativas foi o da Distância de Mahalanobis, apesar de este também englobar, dentro da classe mata em estágio inicial, alguns tipos de cultivo, como café e eucalipto (Figura 3).

Apesar de a proposta de classificação supervisionada da imagem SPOT não ter sido realizada, a opção de fazer interpretação visual da mesma se tornou a mais viável, pois, assim, podemse, posteriormente, contabilizar incrementos e desmatamentos de floresta nativa, comparando-se a classificação visual das fotos aéreas de 1970 com a classificação da imagem SPOT de 2005. Ou seja: classificações são realizadas com metodologias idênticas e de elevado índice de exatidão, apesar da subjetividade do classificador (Figura 4).

Após serem calculadas as áreas dos fragmentos para todas as classificações, identificaram-se primeiramente as matas em estágio inicial de regeneração em 1970, as quais se tornaram em estágio médio a avançado atualmente, ou seja, áreas de regeneração. Para isso, em ambiente SIG, fezse uma interseção dos polígonos correspondentes a estágio inicial em 1970 com os de estágio médio a avançado em 2005. O resultado dessa operação culminou na geração de polígonos correspondentes às áreas que se regeneraram. Semelhantemente a essa operação, para delimitar as matas em estágio médio a avançado em 1970 que se tornaram estágio inicial em 2005, efetuou-se uma interseção entre os fragmentos correspondentes, resultando nas áreas desmatadas.

Curiosamente, verificou-se que nos últimos anos ocorreram mais incrementos de mata do que desmatamentos no município estudado. Aproximadamente, 2.459,80 ha de floresta nativa passaram de estágio inicial de regeneração em 1970 para estágio médio a avançado em 2005, enquanto 101,43 ha de mata foram cortados, passando de estágio médio a avançado em 1970 para estágio inicial em 2005 (Figura 5).

Seguindo o raciocínio anterior, também foi possível identificar as áreas totais em que ocorreram regeneração e desmatamento no município. Assim, nesta análise, foram englobados tanto matas em 


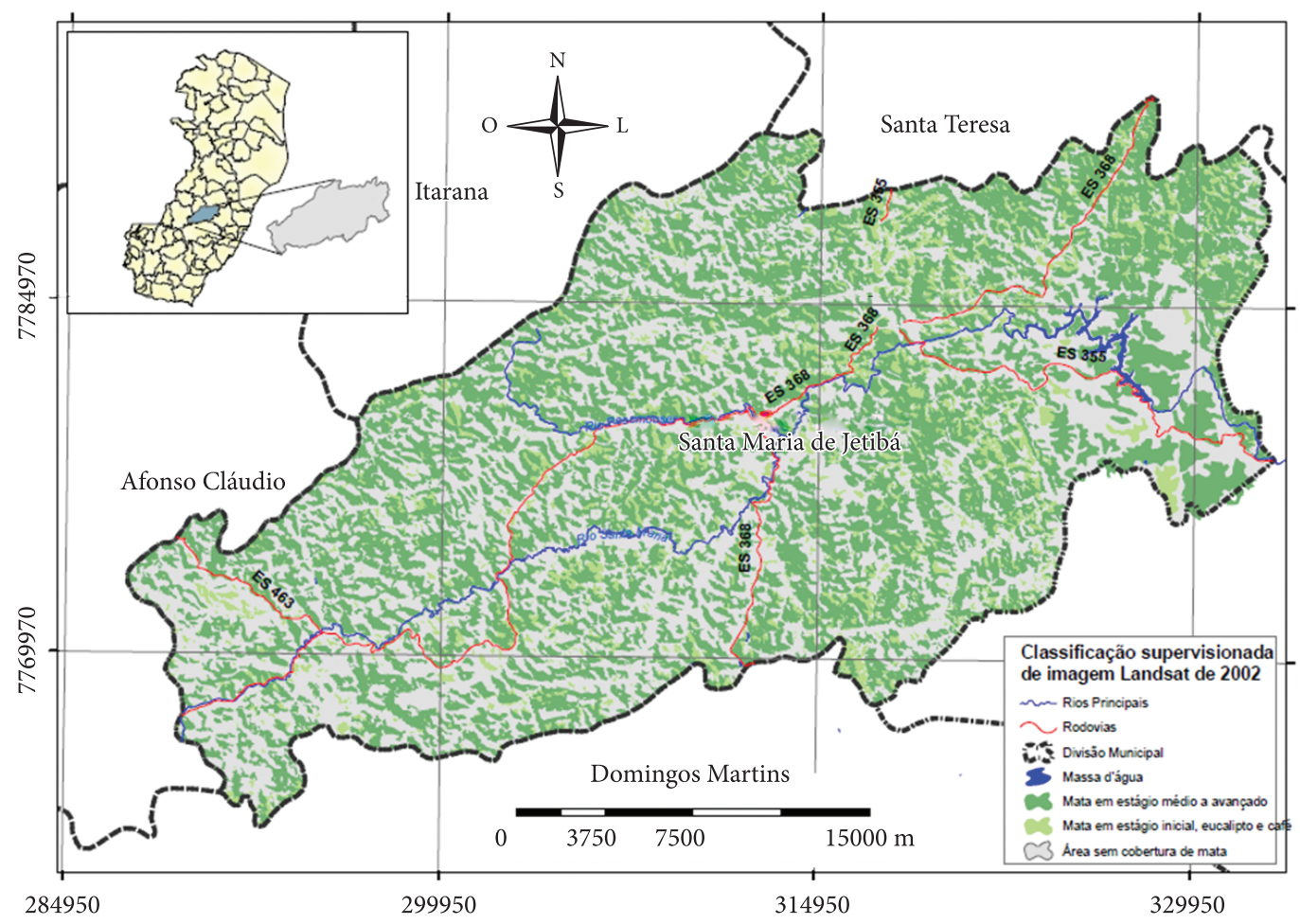

Figura 3. Classificação supervisionada de imagem Landsat de 2002.

Figure 3. Supervised classification of Landsat 2002.

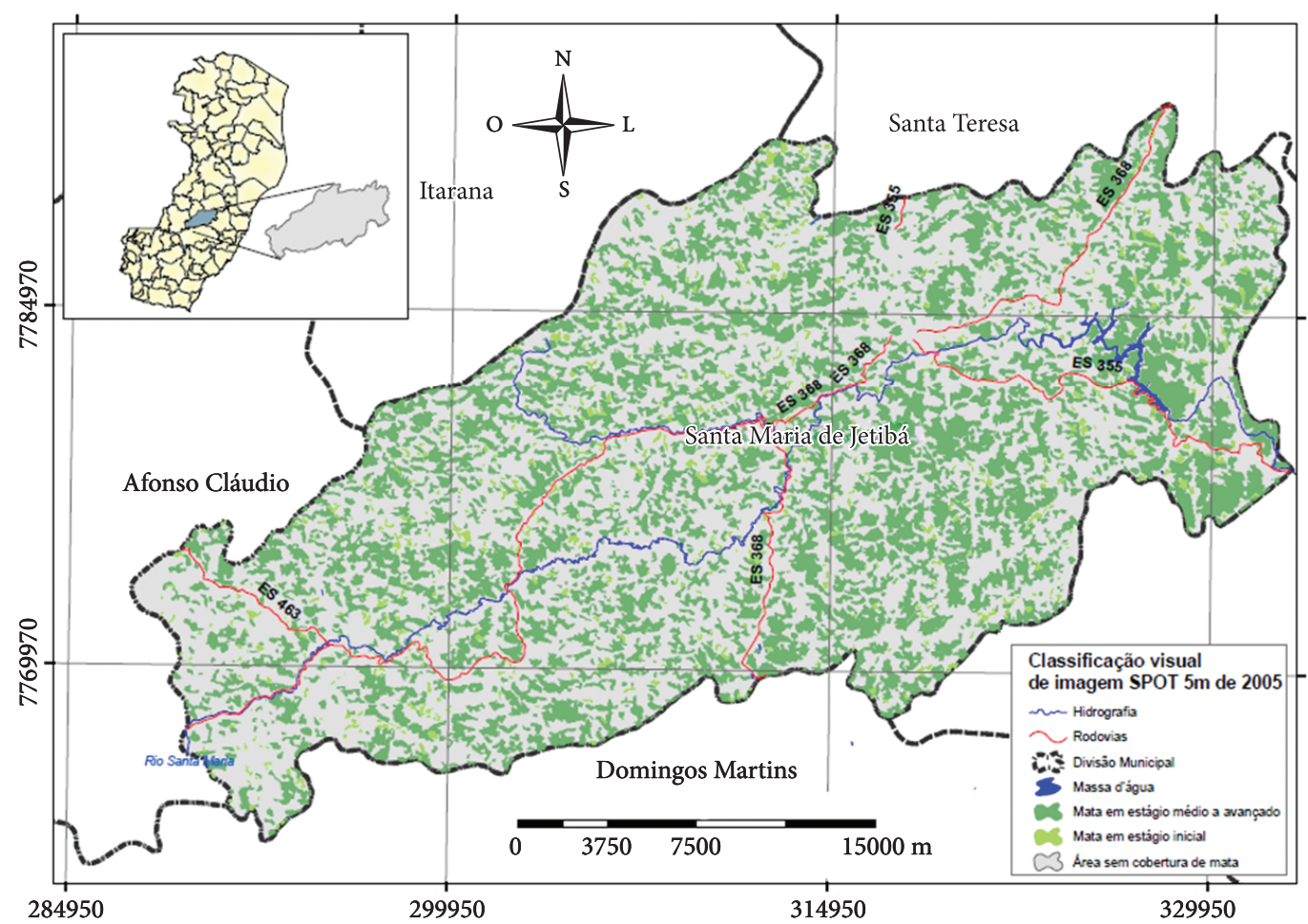

Figura 4. Classificação visual de imagem SPOT 5 m de 2005.

Figure 4. Classification visual image SPOT 5 m 2005. 


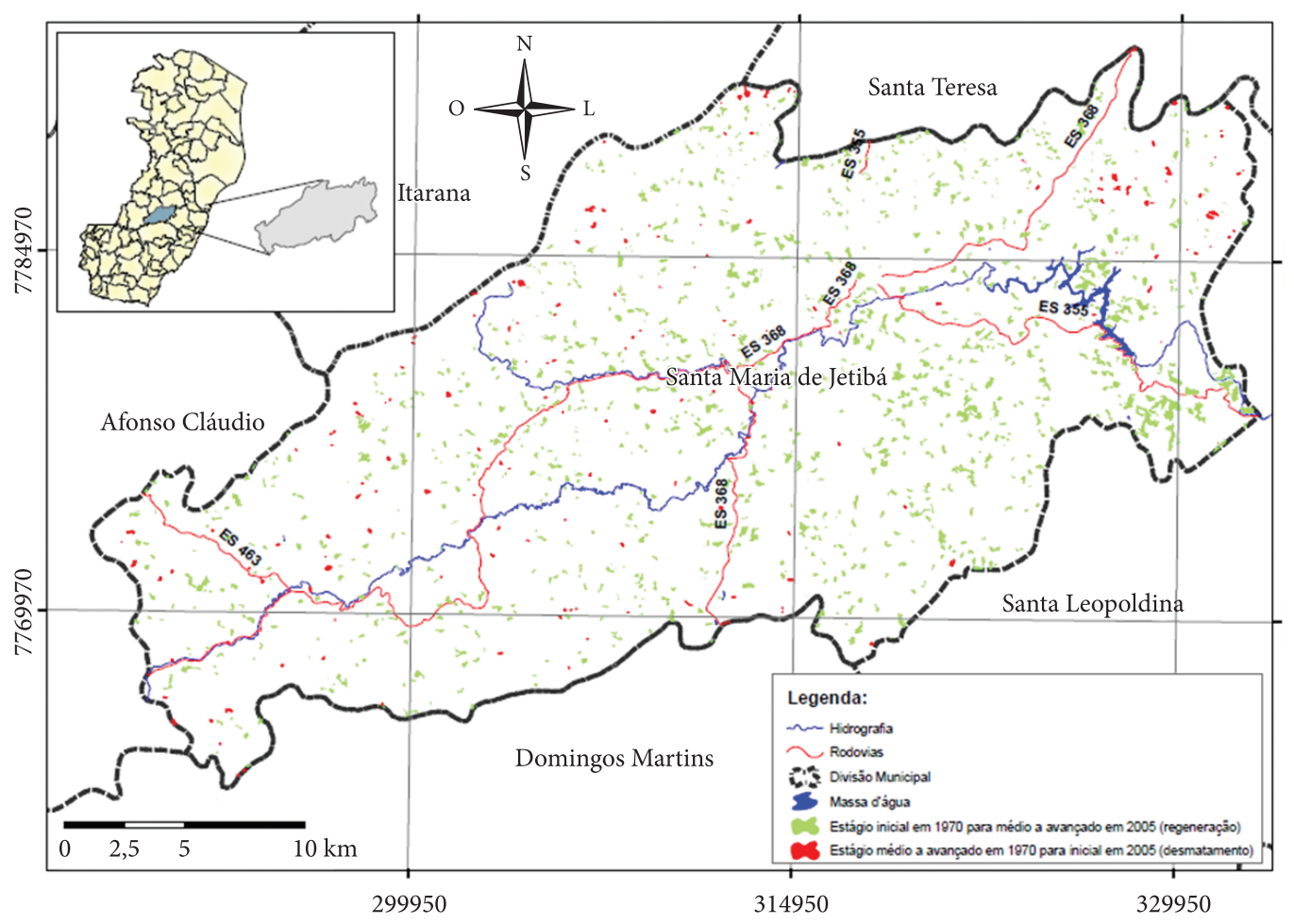

Figura 5. Evolução temporal dos fragmentos florestais.

Figure 5. Temporal evolution of forest fragments.

estágio inicial e estágio médio a avançado de regeneração que sofreram alterações durante os últimos 35 anos.

Para geração dos fragmentos florestais que sofreram regeneração, em ambiente SIG fez-se uma interseção das áreas com ausência de cobertura florestal em 1970 com as áreas que hoje possuem florestas. Já para a identificação dos locais em que ocorreram desmatamentos, bastou fazer a interseção entre as áreas que não possuem fragmentos florestais atualmente com o que era floresta em 1970.

O resultado desse processo matemático mostrou os lugares em que ocorreram regeneração e decrementos de mata, sendo possível também calcular os valores de área e porcentagem (Figura 6).

Cabe lembrar que foram contabilizados e comparados apenas os números adquiridos pelas classificações visuais de 1970 e 2005, posto que são fruto de metodologias idênticas. Assim, pôde-se efetuar uma análise mais confiável sobre a evolução dos fragmentos florestais em Santa Maria de Jetibá. Apesar de a classificação supervisionada de
2002 ter apresentado dados satisfatórios - tendo em vista as limitações de uma imagem de baixa resolução espacial e o fato de a região de estudo ser montanhosa, ocasionando sombra excessiva -, pela aferição de campo, considerou-se que os resultados superestimaram alguns valores, já que a classificação automática incorporou aos pixels de mata em estágio inicial áreas de plantação de café, por exemplo.

Adicionalmente, as assinaturas correspondentes à mata em estágio médio a avançado de regeneração englobaram, em razão da dificuldade encontrada para a correta distinção, algumas áreas de ocorrência de eucalipto e outras de plantações de café na área de vegetação nativa, o que aumentou excessivamente o tamanho dos fragmentos florestais do município e, consequentemente, sua ocupação (Tabela 1).

Mais uma vez, verificou-se que ocorreu um aumento bastante expressivo das áreas de floresta em Santa Maria de Jetibá. Os cálculos mostraram que o município possuía $106,81 \mathrm{~km}^{2}$ de mata em estágio médio a avançado e $41,42 \mathrm{~km}^{2}$ de mata em estágio inicial no ano de 1970, ocupando cerca de 20,13\% do território. Esses números, em 2005, passaram para 


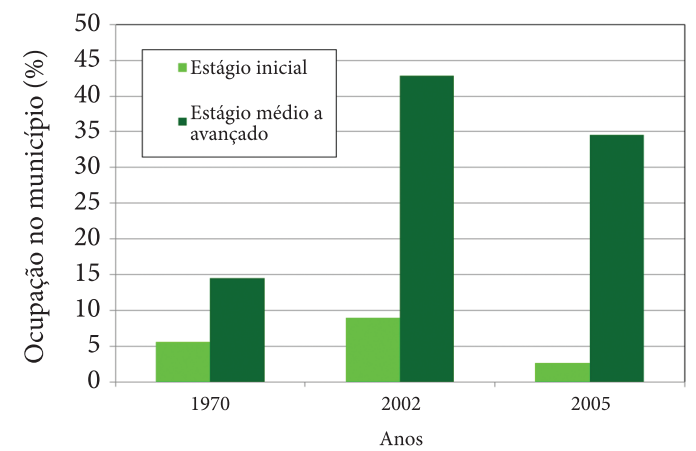

Figura 6. Evolução da cobertura da vegetação no município de Santa Maria de Jetibá-ES, discriminada por estágio de regeneração da vegetação nativa.

Figure 6. Occupation of forest in Santa Maria de Jetiba by type of development stages.

Tabela 1. Evolução da cobertura florestal nos períodos estudados.

Table1. Evolution of forest fragmentation during periods studied.

\begin{tabular}{ccc}
\hline Ano & Área $\left.\mathbf{( k m}^{\mathbf{2}}\right)$ & Porcentual (\%) \\
\hline 1970 & 148,2 & 18,5 \\
\hline 2002 & 381,2 & 47,5 \\
\hline 2005 & 273,7 & 34,0 \\
\hline TOTAL & 803,1 & 100,0 \\
\hline
\end{tabular}

$254,31 \mathrm{~km}^{2}$ de mata em estágio médio a avançado e $19,34 \mathrm{~km}^{2}$ de mata em estágio inicial, totalizando cerca de $37,17 \%$ de ocupação do município estudado. A partir desses números, constatou-se que houve um incremento de 17,04\% nas florestas de Santa Maria (Figura 7).

Desde sua origem, o sensoriamento remoto tem sido usado como uma importante e estabelecida ferramenta para a geração de dados por meio da aerofotogrametria, para inúmeras aplicações agrícolas, incluindo monitoramento e estimativa da produção agrícola. Muitas companhias e governos necessitam dessas estimativas para poder planejar os seus requerimentos para processamento e armazenamento, bem como planejar estratégias para a comercialização.

Apesar de o sensoriamento remoto já ser uma ferramenta bem estabelecida para esses fins, fotografias aéreas não são capazes de um número suficiente de amostras estatisticamente aceitas ou de cobrir áreas extensas o bastante para uma estimativa precisa das culturas agrícolas. Consequentemente, torna-se oportuno expandir os

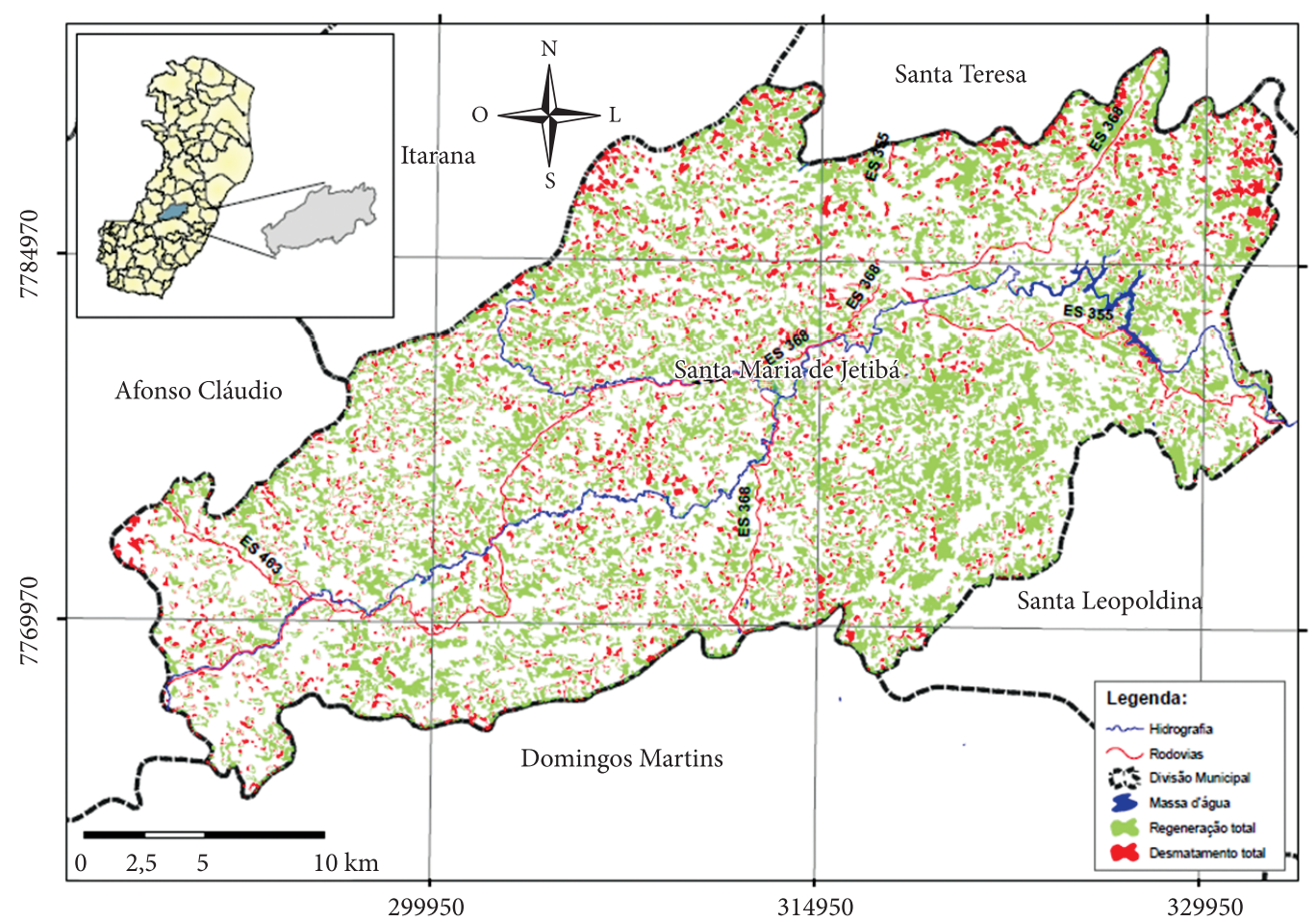

Figura 7. Regeneração e desmatamento totais ocorridos nos últimos 35 anos.

Figure 7. Regeneration and total deforestation over the past 35 years. 
limites do sensoriamento remoto para incorporar imagens obtidas por plataformas orbitais (imagens de satélites), uma vez que esses tipos de imagens são capazes de prover uma melhor amostragem e cobrir áreas mais extensas.

Apesar de estarem disponíveis várias estratégias para a classificação de imagens orbitais, não existe, ainda, uma metodologia capaz de gerar produtos com precisão compatíveis com as requeridas para esse tipo de estimativa (Vieira et al., 2000).

Para aplicações práticas, é essencial que o sistema de classificação seja robusto, ou seja, que possa ser facilmente extrapolável para outras áreas e situações. Assim, pesquisas devem buscar métodos alternativos para alcançar melhores performances no processo de classificação.

Considerando-se a problemática apresentada, dois objetivos gerais podem ser considerados para desenvolver futuras pesquisas nesse tópico:

- Desenvolver uma metodologia eficiente para classificar o uso do solo, levando em consideração o aspecto multitemporal, multissensor e mutiespectral das imagens proveniente do sensoriamento remoto, e realizar uma investigação dos custos absoluto (tempo de processamento) e relativo (melhoria na precisão) envolvidos na incorporação da dimensão temporal no processo de classificação.

- Usar vários algoritmos, como: verossimilhança (Maximum Likelihood), regra da mínima distância euclidiana e redes neurais artificiais, bem como combiná-los com o intuito de melhorar a precisão da classificação. Devem-se explorar as bases teóricas sobre as quais cada uma dessas técnicas está baseada.

Considerando-se a grande importância das informações provenientes do sensoriamento remoto para avaliação e monitoramento dos recursos naturais, pesquisas devem ser desenvolvidas para a determinação de sua confiabilidade e potencial utilização.

Um grande número de metodologias tem sido desenvolvido para a classificação (ou identificação) automática das imagens oriundas do sensoriamento remoto (Vieira \& Mather, 2000). Os procedimentos, atualmente em uso, baseiam-se na simples investigação da característica radiométrica do pixel (análise multispectral), sem considerar a possível transformação dessas características no tempo (análise multitemporal) e no espaço (textura). Esses métodos tradicionais implicitamente assumem que, para a subclasse vegetação, o estágio fenológico de crescimento é o mesmo em um dado momento.

Contudo, mesmo considerando uma área homogênea, essa suposição não é válida, em função dos diferentes tempos de plantio e dos diferentes tipos de solo e condições climáticas. E essa caracteríatica faz com que a distribuição de probabilidades não seja unimodal, o que pode ser um fator limitante para alcançar alta precisão na classificação usando-se os métodos estatísticos tradicionais.

\section{CONCLUSÃO}

A partir dos resultados obtidos neste trabalho, pode-se inferir que:

- Com as classificações, foi possível fazer comparações, analisando e identificando, em cada período, desmatamentos e incrementos de floresta nativa.

- Os processos de segmentação e classificação supervisionada de imagens do satélite Landsat-TM, disponíveis no ERDAS Imagine 8.5, mostraram-se ser eficientes para mapeamentos na escala de 1:50.000

- Houve incremento de mata bastante expressivo, se comparado aos desmatamentos.

- Entre os anos de 1970 e 2005, houve um incremento de 17,04\% nas florestas nativas de Santa Maria de Jetibá.

\section{STATUS DA SUBMISSÃO}

Recebido: 25/10/2011

Aceito: 25/03/2012

Publicado: 30/09/2012

\section{AUTOR PARA CORRESPONDÊNCIA}

\section{Alexandre Rosa dos Santos}

Departamento de Engenharia Rural - ERU, Universidade Federal do Espírito Santo - UFES, Bairro Universitário, SN, CEP 29500-000, Alegre, ES, Brasil e-mail: mundogeomatica@yahoo.com.bre alexandre.santos@pq.cnpq.br 


\section{Fernando Coelho Eugenio}

Departamento de Engenharia Florestal, Centro de Ciências Agrárias, Universidade

Federal do Espírito Santo - UFES, Alto Universitário, s/n, CEP 29500-000, Alegre, ES, Brasil,

e-mail: coelho.fernando@yahoo.com.br

\section{REFERENCIAS}

Brites RS. Verificação de exatidão em classificação de imagens orbitais: efeitos de diferentes estratégias de amostragem e avaliação de índices de exatidão [doutorado]. Viçosa: Universidade Federal de Viçosa; 1996.

Congalton RG, Green K. Assessing the accuracy of remotely sensed data: principles and practices. New York: Lewis Publishers; 1999. 136 p.

Congalton RG. A comparison of sampling schemes used in generating error matrices for assessing the accuracy of maps generated from remotely sensed data. Photogrammetric Engineering and Remote Sensing 1988; 54(5):593-600.

Crósta AP. Processamento digital de imagens de sensoriamento remoto. Campinas: IG/ UNICAMP; 1992. 170 p.
Instituto Brasileiro de Geografia e Estatística - IBGE. Dados históricos do Censo. 1975. Available from: http:// www.ibge.gov.br/dados.

Instituto Brasileiro de Geografia e Estatística - IBGE. Dados históricos do Censo. 2001. Available from: http:// www.ibge.gov.br.

Richards JA. Classifier performance and map accuracy. Remote Sensing of Environment 1996; 57:161-166. http:// dx.doi.org/10.1016/0034-4257(96)00038-7

Ryherd S, Woodcock C. Combining spectral and texture data in the segmentation of remotely sensed images. Photogrammetric Engineering \& Remote Sensing 1996; 62(2):181-194.

Santos AR, Peluzio TMO, Saito NS. SPRING 5.1.2: passo a passo: aplicações práticas. Alegre: CAUFES; 2010. 153 p.

Thompson SK. Sampling. 2rd ed. New York: John Wiley \& Sons, Inc.; 2002. 343 p.

Vieira CAO, Mather PM. (2000) A comparative study of multiple classifier combination methods in Remote Sensing. In: Proceedings of the International Conference on Artificial Intelligence - IC-AI; 2000; Las Vegas. Las Vegas; 2000, p. 39-46.

Vilela MF. Integração de técnicas de geoprocessamento e levantamento participativo de informações socioambientais: um subsídio para a reforma agrária [doutorado]. Viçosa: Universidade Federal de Viçosa; 2002. 